\title{
103 \\ Experimentation in Telelearning Environments: 3 Case Studies
}

\author{
Chair: Robert Munro (UK) \\ Panel: Ken Eustace (AU), France Henri (CA), Wolfgang Weber (DE)
}

Keywords: distance learning, leaming systems, collaborative learning, leaming materials, management

This panel offered WCCE 2001 participants the opportunity to hear about and reflect on research conclusions associated with innovative practice in telelearning which aimed to promote a sense of community amongst participants.

While distance provision holds many attractions and resolves many educational problems, concern has focussed on the importance of creating rich learning environments and enhancing opportunities for group collaboration and co-operation.

The three presenters were keen to illustrate that learning is most effective when the learner is placed at the centre of the instructional model and value is derived from a greater community of learning. This panel attracted considerable interest - not least because of the experience in telelearning offered by the panel members but also because of the geographical perspective of these experiences.

Dr. Ken Eustace, director of the Research Unit for Telelearning Environments in the School of Information Studies at Charles Sturt University in Australia, works with various research groups and has considerable experience in installing, using and testing ICT tools. In exploring the added value of text-based synchronous workshop practice (ranging from raw telnet to full web interfaces) he has built up many effective learning communities on-line. 
These have included Virtual Conferences, a Literature Circle Network linking primary schools in New South Wales and Tasmania, and the Executive meetings of National Societies such as the Australian School Libraries. All have demonstrated significant advantages over more conventional interactions.

Ken maintained it was vital that developers of virtual environments and learning communities made it simple to connect participants and provided adequate scaffolding and support for development and interaction. He considered it important that people were given time to explore the medium and develop/refine their skills in using ICT facilities. Ken envisaged three principal stages in a developing community - the initial socialisation period where introductions were made and stories and photographs might be swapped, an alliance building phase and finally the critical stage where participants worked as a team on project work.

He identified four main issues:

- Ensuring ethical use of computers by all

- Rights, responsibilities and behaviours for group protocol

- Intellectual property rights

- The shift in focus from instructor to learner with flatter hierarchical structures.

France Henri is a professor at the Télé-université of Montreal in Canada. This distance teaching university has more than 25,000 students and operates in many respects like the Open University in the United Kingdom. Teachers/professors at the University design and create learning environments for their courses/students and, once these are effected, students are free to interact and learn in the environments. There is no face-to-face teaching.

Five principal zones or spaces comprise the generic model for the construction of these learning environments:

- Information space which holds the content

- Management space which facilitates organisation and navigation

- Assistance space offering human or automated help systems

- Production space where development can take place

- Collaboration space.

Aided by a very comprehensive slide Ms. Henri illustrated the importance of the collaboration space. Here students develop their group identity - they bond and don't feel they are studying in isolation. The space offers resources and tools for sharing and for stimulating co-operation and collaboration and provides contacts to other students and a range of computer conferences.

In the Télé-université model on-line teaching has no place. The model is based on flexibility and autonomy - no professors or tutors tell the students 
what to do. Students are in control of, and are responsible for, their own learning. They study what they want when they want and at any depth. This approach neutralises the traditional model of learning employed in schools and promotes both individual and co-operative or collaborative approaches to learning - as and when necessary.

Wolfgang Weber is the Head of The Advisory Centre for New Technologies in The North Rhine Westphalian State Institute for School and Adult Education, Soest, Germany and their server provides learning environments for schools and colleges. Importantly, topic-oriented resources, detailed background information on a range of issues and lists of contacts are provided. Topics range from general information for primary school pupils to specific issues e.g. the environmental impact of air pollution/acid rain for College science courses. Message boards are accessible to participants who can interchange information and opinions. Mediators of these boards can select participants, restrict access and establish small group discussion areas. A media centre allows teachers and pupils to access different media resources and the 'Foyer' offers a publishing room. In addition 'workshop rooms' provide collaborative space where pupils from different schools can work on projects of communal interest. Audio conferencing, video-chat and white board communication workspace is available.

The system has been extensively tested in local primary and secondary schools. Institutions in North Rhine Westphalia and the Sud-Tirol area of Northern Italy have been linked. Teacher training and in-service courses are offered on how to use the system and materials development groups have been set up.

Some key considerations underpinned the design of the environment:

- Participants should have equal or similar rights of access

- They should preferably get to know each other face-to-face

- There must be structure to the planned work or co-operation.

The telelearning exemplars exhibited many similarities and addressed common issues of access, equity and collaboration. The presentations sparked a number of questions and particular interest was expressed in the importance of structure in designing the environments. The panel members stressed the importance of creating/choosing carefully structured tasks for participants and of designing the learning environment specifically and appropriately for the 'client group'. The better, more thoughtful, and more appropriate the design and structure then the more flowing the discussion and collaboration. Ken Eustace suggested that at the end of a course people wanted to meet to socialise and discuss. If they have faces to fit to writing styles this promotes both socialisation and discussion. France Henri and 
Wolfgang Weber noted similar responses from users of their systems. The desire for socialisation is present no matter the age of participants.

All of the systems build in opportunities for co-operation and collaboration and this raised the question as to whether the problem-based work was largely individual or do the students genuinely co-operate? France Henri stressed that, while she always tried to build in a collaborative element, there must be a balance between individual and collaborative work. The Télé-université favoured a team or large group project set up early in the course. Wolfgang Weber said co-operation was an important consideration and was often related to the topic under investigation and the level at which students were exploring the material. With increased collaboration management issues became significant. Ken Eustace felt that the cooperative or collaborative element helped reduce feelings of isolation and built up self-esteem. As a result it was often difficult to close off the collaboration!

Following further detailed questioning the panel concluded that the telelearning community must urgently address cross-cultural issues, plagiarism and intellectual property/copyright matters. 